\title{
Fn14 receptor promotes invasive potential and metastatic capacity of non-small lung adenocarcinoma cells through the up-regulation of integrin $a 6$
}

\author{
J. JANDOVA ${ }^{1,2^{*}}$, C. J. MASON ${ }^{1}$, S. C. PAWAR ${ }^{1,3}$, G. S. WATTS ${ }^{1,3}$ \\ ${ }^{1}$ University of Arizona Cancer Center and Departments of ${ }^{2}$ Medicine - Dermatology Section and ${ }^{3}$ Pharmacology, University of Arizona, Tucson, \\ AZ 85724, USA
}

*Correspondence: jjandova@email.arizona.edu

Received February 14, 2014/ Accepted May 26, 2014

\begin{abstract}
Lung cancer is one of the leading cause of cancer-related death around the world with the majority of diagnoses being non-small cell lung cancer (NSCLC). Given the poor survival rate and efficacy of current therapy for NSCLC, there is a need to identify and develop new therapeutic targets for treatment. We have observed significantly up-regulated levels of Fn14 in clinical samples of lung cancer relative to normal adjacent tissue. However, the functional role of Fn14 in these tumors is not understood yet. We used RT-PCR to establish the Fn14 expression profile in various NSCLC cell lines. Using isogenic variants of H460 NSCLC cell line with low, intermediate and high Fn14 expression as a cellular model, we determined that increased levels of integrin $a 6$ in cells over-expressing Fn14 is suggestive of an important role of a6 $\beta 1$-fn14 interactions in motility of lung carcinoma and formation of metastases. Enhanced levels of Fn14 correlated with higher tumor cell migration and invasion in an MMP-1 dependent manner. Cells over-expressing Fn14 showed increased in vivo tumor formation with metastatic capacity to lymph nodes, lungs and liver. Thus, this research may be a step toward developing improved treatment strategies for NSCLC by improved detection and inhibition of metastases.
\end{abstract}

Key words: Fn14, TNFRSF12A, non-small cell lung cancer, H460 cells, motility, tumor formation and metastasis, integrin $\alpha 6$

Lung cancer is the most common cancer in the world [1] and is the leading cause of cancer-related death around the world with the majority of diagnoses being non-small cell lung cancer (NSCLC) including both squamous carcinoma and adenocarcinoma. NSCLC accounts for over $85 \%$ of lung cancer cases with the 5-year survival rate only $14 \%$ [2,3]. Although tobacco smokers make up the majority of lung cancer cases, up to $20 \%$ of lung cancers are in never-smokers $[2,4]$. The American Cancer Society reported in 2008 that even after removing smoking-related lung cancer deaths, lung cancer in never-smokers is estimated to be the third leading cause of death in men and fifth leading cause of death in women [5]. Besides smoking, environmental exposure to pollutants in automobile exhaust, coal burning emissions, arsenic and other metals, asbestos and radon gas are known to cause lung cancer [6-8].

Treatments for NSCLC after mediastinum lymph node evaluation may involve partial or full lung removal for those with no evidence of lymph node involvement and patients with mediastinum lymph node connection undergo pre and post-operative chemotherapy, surgery and radiotherapy. Surgical treatment prolongs life at best by 10 months however; NSCLC is often metastatic leading to a poor prognosis for most patients diagnosed [9]. Whitsett et al. recently observed that Fn14 (TNFRSF12A), a member of the tumor necrosis factor super-family of cell surface receptors, is significantly up-regulated in clinical samples of lung cancer relative to normal adjacent tissue what makes it an attractive target for use as a tumor marker and therapeutic target to improve the survival rates of NSCLC [3].

Fibroblast growth factor-inducible 14 (Fn 14; gene TNFRSF12A) is a type 1 transmembrane protein comprised of 129 amino acids and the smallest known member of tumor necrosis factor superfamily of receptors [10] found on chromosome 16 [11]. Fn14 is most commonly known as the receptor for a multifunctional cytokine tumor necrosis factor-like weak inducer of apoptosis (TWEAK) which has been reported to induce a broad range of responses from apoptosis to cellular invasion, migration and survival [12]. Increased levels of Fn14 are often seen in tumor cells rela- 
tive to low levels in normal cells [13]. Fn14 up-regulation has been observed in a variety of cancer cell lines such as breast, brain, bladder, skin, lung, ovarian, pancreatic, colon, prostate and cervical cancer cell lines [14] as well as in several solid tumors [15] including hepatocellular carcinoma [16], glioblastoma [17,18], gastrointestinal cancer [19], urothelial carcinoma [20], malignant ovarian tumors [21], prostate [22] and breast carcinoma [23]. Thus, increased expression of Fn14 might be indicative of cancer and suppression of its expression could be a possible therapeutic target to inhibit development and progression of various cancers. Increased expression of Fn14 has suggested its invasive properties in urothelial carcinoma [20]. Fn14 expression was detected in the majority of tumor types, including pancreatic cancer (60\%), bone metastases (54\%) and liver metastases in colorectal cancer (50\%) [24]. High levels of Fn14 or TWEAK were observed in $60 \%$ of patients with esophageal cancer and $75 \%$ of patients with pancreatic cancer as well as in majority of human esophageal and pancreatic cell lines [13]. Yoriki et al. demonstrated the functional importance of Fn14/TWEAK pathway in pancreatic cancer progression [19]. Expression of TWEAK/Fn14 proves to be a marker for malignant ovarian tumors [21]. Huang et al. suggested that overexpression of Fn14 may contribute to multiple malignant cellular phenotypes associated with prostate cancer progression [22]. Two research groups recently reported the up-regulation of Fn 14 in NSCLC specimens $[3,24]$. However, the functional role of Fn14 in this type of tumors is not understood yet.

The mobility of malignant tumor cells depends on complex molecular interactions that regulate the structure, function, and interactions of cytoskeleton and extracellular matrix. Integrins are a family of dimeric, transmembrane proteins that mediate cell-cell and extracellular matrix adhesion and signals transduced by integrins play a role in many biological processes, including cell growth; differentiation, migration and apoptosis [25]. Increased levels of Fn14 are often indicative of enhanced motility of tumor cells. In addition, expression-correlated set of genes including Fn 14 and integrin $\beta 1$ functions in molecular interaction networks promoting cellular migration via structural changes and signaling [26]. However, there is still very limited information available about the interactions between Fn14 and integrins that might be involved in cancer cell motility and metastases.

In this study we demonstrate a functional role of Fn14 in carcinogenesis of non-small lung carcinoma. We show that Fn14 can induce the expression of integrin $a 6$ which is necessary to promote the migration, invasion and metastases formation of H460 non-small cell lung carcinoma cells. Moreover, we report that over-expression of Fn14 can increase the expression of various nuclear encoded genes known to be associated with malignant transformation of cells such as MMP-1. Furthermore, cells producing high levels of Fn14 showed significantly increased tumor formation, both in vitro and in vivo with increased metastatic capacity to lymph nodes, lungs and liver. Thus, Fn14 may serve as a tumor marker for lung carcinoma and as a novel therapeutic target for improving the survival rates of NSCLC.

\section{Materials and methods}

Cell culture and tissue collection. H460, non-small cell lung adenocarcinoma cell line was obtained from American Type Culture Collection (ATCC, Manassas, VA) for in vitro and in vivo studies. Cells were maintained in Dulbecco's modified eagle medium (DMEM; Gibco-BRL, Rockville, MD) and $10 \%$ fetal bovine serum supplemented with $50 \mu \mathrm{g} / \mathrm{ml}$ penicillin/streptomycin (Invitrogen, Carlsbad, CA) in a 5\% carbon dioxide $/ 95 \%$ environment at $37^{\circ} \mathrm{C}$. All isogenic variants of H460 cancer cells were maintained in Dulbecoo's modified eagle media supplemented with $10 \%$ fetal bovine serum, $50 \mu \mathrm{g} /$ $\mathrm{ml}$ penicillin/streptomycin and $2 \mu \mathrm{g} / \mathrm{ml}$ of selective antibiotic Blasticidine at $37^{\circ} \mathrm{C}$ and $5 \%$ carbon dioxide.

Lentivirus transduction. Lentiviral constructs were created to test the effect of Fn14 expression in H460 lung adenocarcinoma cells.

To generate H460 cells with stable Fn14 overexpression, full length Fn 14 cDNA clone along with PCR primers for amplification and modification of the resulting product for TOPO directional cloning were obtained from the American Type Culture Collection (ATCC, Manassas, VA) and Biosynthesis (Lewisville, TX), respectively. The FN14 cDNA was PCR amplified from the original ATCC vector with Pfx polymerase to generate blunt-end PCR products for directional cloning into the expression pLenti6/V5-D-TOPO vector which was designed to facilitate rapid TOPO cloning and high level expression of PCR products in mammalian cells using ViraPower Lentiviral Expression System (Invitrogen, Carlsbad, CA). pLenti6/V5-GW/lacZ was used as a positive control expression vector. This vector contains human cytomegalovirus (CMV) immediate early promoter for high-level constitutive expression of the gene of interest. Using the ViraPower Lentiviral Expression System, we were able to create a replication-incompetent, HIV-1-based lentivirus that was used to deliver and express Fn 14 in H460 cells.

To create H460 cells with stably silenced Fn 14 expression, two shRNAs directed against the Fn14 mRNA were designed using the Invitrogen's proprietary design software from siRNA sequences previously used in Fn14 transient transfection experiments (Invitrogen, Carlsbad, CA). Two strands of shRNA sequences targeting FN14 mRNA were synthesized (5' - CACCGCAGGAGAGAGAAGTTCACCACGAATGGTGAACTTCTCTCTCTTGC - 3' and 5' - CACCGCCACTCATCATTCATTCATTTCGAAAAATGAATGAATGATGAGTGG - 3'), annealed and cloned into the entry pENTR/U6 vector which contains attL sites to facilitate transfer of the U6 RNAi cassette into the destination pLenti6/BLOCK-iT-DEST vector to generate an expression clone. To obtain pLenti6/BLOCK-iT expression clone, the LR clonase reaction between entry and destination construct was performed using the Block-iT Lentiviral RNAi Expression 
kit (Invitrogen, Carlsbad, CA) according to manufacturer's instructions with some modifications. The expression clone was then packaged into the lentiviral particles and used to stably transduce $\mathrm{H} 460$ cells with shRNA targets against Fn14 mRNA. pLenti6-GW/U6-laminshRNA plasmid was used as a positive control for lentivirus production.

Quantitative Real-Time reverse transcriptase Polymerase Chain Reaction (RT-PCR). Total RNA extraction from all isogenic variants of $\mathrm{H} 460$ cells was performed using RNAeasy Minikit (QIAGEN, Valencia, CA). Human Fn14 (Hs00171993_A1), ITGA6 (Hs01041011_m1) and GAPDH (Hs99999905_A1) primer/probes were obtained from Applied Biosystems (Branchburg, NJ). cDNA was synthesized from $500 \mathrm{ng}$ of total RNA in a $50 \mu \mathrm{l}$ reaction with master mix containing 10xRT buffer, $5.5 \mathrm{mM} \mathrm{MgCl}_{2}, 2 \mathrm{mM}$ dNTPs, $2.5 \mu \mathrm{M}$ random hexamers, 2 units of RNase Inhibitor and 62.5 units of Multi Scribe Reverse Trascriptase. All MasterMix reagents were purchased from ABI (Applied Biosystems, Branchburg, NJ). Reactions were performed in MJ Thermocycler PTC-200 (MJ Research, Watertown, MA) followed by these conditions: $25^{\circ} \mathrm{C}$ for 10 minutes, $48^{\circ} \mathrm{C}$ for 30 minutes and $95^{\circ} \mathrm{C}$ for $5 \mathrm{~min}$ utes. 10ng of cDNA was then used to amplify the human Fn 14 and integrin $a 6$ (ITGA6) sequence. The conditions for PCR reactions were: 10 minutes at $95^{\circ} \mathrm{C}$ followed by 15 seconds at $95^{\circ} \mathrm{C}, 1$ minute at $60^{\circ} \mathrm{C}$ for 40 cycles by using ABI7000. PCR amplification of the human GAPDH was used to control quality of the cDNA. Non-template controls were included on each PCR plate. mRNA expression levels of Fn14 and ITGA6 were normalized to the GAPDH control. Amplification plots were generated and the $\mathrm{Ct}$ values (cycle number at which fluorescence reaches threshold) recorded.

Immunoprecipitation and western blot analysis. Cell lysates from all Fn14 isogenic variants of H460 cells were prepared by harvesting the cells in RIPA lysis buffer containing 50mM Tris, $\mathrm{pH} 7.4,150 \mathrm{mM} \mathrm{NaCl}, 1 \mathrm{mM}$ EDTA, $1 \%$ Triton N-100, $1 \%$ sodium deoxycholate and $0.1 \%$ sodium dodecyl sulfate and protease inhibitor mixture (Leupeptin, Aprotinin, PMSF). Cell lysates were pre-cleared with protein A/G PLUS Agarose beads (Santa Cruz Biotechnology, Santa Cruz, CA) and then the protein concentration was measured using BioRad Protein Assay (Hercules, CA). Equal amounts of pre-cleared protein $(1 \mathrm{mg})$ were then incubated with $3 \mu \mathrm{g}$ of either rabbit monoclonal antibody against Fn14 (ITEM1), mouse monoclonal antibody against human $\alpha 3$ integrin; clone P1B5, or rabbit monoclonal antibody against human $a 6$ integrin; clone $\mathrm{J} 1 \mathrm{~B} 5$ at $4^{\circ} \mathrm{C}$ overnight. Then protein A/G PLUS Agarose beads were added to each sample and incubated at $4^{\circ} \mathrm{C}$ for 1 hour to remove Fn14, $\alpha 3$ or $\alpha 6$ integrin. Beads were washed three times with cold PBS and $2 x$ protein loading dye added to each bead pellet. To release the Fn14 or integrins from the beads to the loading dye, samples were denaturated at $95^{\circ} \mathrm{C}$ for 5 minutes and then separated by either $12 \%$ or 7.5\% SDS-polyacrylamide gel electrophoresis followed by transfer to PVDF membranes. The membranes were blocked with 5\% nonfat dry milk in Tris-buffered saline, $\mathrm{pH} 8.0$, with
$0.1 \%$ Tween 20 for 1 hour prior to an addition of primary western blot antibodies, followed by secondary anti-mouse or anti-rabbit horseradish peroxidase-conjugated antibodies. Control mouse anti human $\beta$-actin primary antibody was obtained from Sigma-Aldrich (St. Louis, MO), rabbit anti-Fn14 (ITEM-1) monoclonal antibody from Abcam (Cambridge, MA), mouse anti- $\alpha 3$ integrin antibody (clone P1B5) from Millipore (EMD Millipore Corporation, Billerica, MA); rabbit anti- $\alpha 6$ integrin antibody (clone J1B5) and AA6 $\alpha$ antibody for western blot detection of both $\alpha 3$ and $\alpha 6$ integrins were greatly provided by Dr. Cress from the University of Arizona[27,28]. Secondary anti-mouse or anti-rabbit antibodies were obtained from Sigma-Aldrich (St. Louis, MO). Protein bands were identified by chemiluminescence and exposed on X-Omat AR film (Eastman Kodak Co., Rochester, NY).

Transwell migration assay. This assay was performed as described previously $[29,30]$. Briefly, eight micrometer pore size translucent transwell migration chambers (BD Biosciences, Bedford, MA) in 24-well plate were used for migration analysis. Briefly, $600 \mu \mathrm{l}$ of invasion buffer (DMEM media with $0.5 \% \mathrm{FBS}, 0.1 \% \mathrm{BSA}$ and without antibiotics) was added to each well, and 100ul of $\mathrm{H} 460$ isogenic variants suspended in invasion buffer at concentration of $15 \times 10^{5} / \mathrm{ml}$ was plated on the top of the membrane. After overnight incubation of 18 hours at $37^{\circ} \mathrm{C}, 5 \% \mathrm{CO}_{2}$, membranes were stained with $0.5 \%$ crystal violet in $20 \%$ methanol for 1 minute. The stain was rinsed off thoroughly with water, cells remaining on the top of the migration chamber were removed by lightly swabbing, and stained cells adhering to the bottom of the chamber were counted.

Invasion assay. Cell invasion was performed as described previously [30] using Matrigel ${ }^{\mathrm{TM}}$ pre-coated membrane filters (BD Biosciences, Bedfold, MA). A monolayer of cells (75\% confluence) was suspended in $100 \mu$ of Dulbecco's modified Eagle's medium containing $1 \mathrm{mg} / \mathrm{ml}$ bovine serum albumin and $0.5 \%$ fetal bovine serum only or the same media but supplemented either with $5 \mu \mathrm{M}$ anti-MMP-1 blocking antibody (R\&D Systems, Minneapolis, MN) or $15 \mu \mathrm{M}$ irreversible inhibitor of NF- $\kappa$ B activation Bay11-7082 (EMD Millipore Corporation, Billerica, MA). Transwell inserts were then incubated for 24 hours at $37^{\circ} \mathrm{C}$ and $5 \% \mathrm{CO}_{2}$. Non-invading cells were removed by wiping the upper side of the membrane, and invading cells that had crossed through the transwell barrier were fixed with methanol and stained with crystal violet. The number of invading cells was quantified by counting ten random fields (total magnification, X 200) per filter.

Image analysis of transwell migration assays. The 24well BD Falcon cell culture companion plates for inserts (BD Biosciences, Bedfold, MA) were analyzed for migration/ invasion of $\mathrm{H} 460$ isogenic cell line variants through the translucent transwell membrane (8.0um pore size, $1.0 \times 10^{5}$ pore density). Images of 14 fields per transwell were captured from each well using a $10 \mathrm{X}$ objective in combination with a $1.5 \mathrm{X}$ optivar. Image capture was performed with an Olympus IMT2 microscope (Olympus America Inc., Center Valley, PA), 
a Hamamatsu ORCA-100 greyscale CCD camera (Hamamatsu USA, Bridgewater, NJ), and a Ludl motorized XY stage (Ludl Electronic Products, Hawthorne, NY). The camera and stage was computer controlled by SimplePCI software version 6.2 (Compix Inc., Sewickley, PA). After the images were captured, the SimplePCI software created a binary image by performing an intensity threshold, than performed a size exclusion to avoid measuring the membrane pores, and the remaining binary image was measured for the area.

Soft agar colony forming assay. 3\% agar in sterile water was autoclaved and kept in water bath at $48^{\circ} \mathrm{C}$. The agar was then diluted in normal growth media (pre-warmed in $48^{\circ} \mathrm{C}$ water bath) to the final concentration of $0.6 \% .4 \mathrm{ml}$ of $0.6 \%$ agar was then added as a bottom layer into the 6-well plates. After the solidification in a cell culture hood at room temperature, the top layer was prepared by mixing the $0.6 \%$ agar $\left(48^{\circ} \mathrm{C}\right)$ and $20 \times 10^{4}$ of isogenic variants of $\mathrm{H} 460$ cells at $37^{\circ} \mathrm{C}$ in $1: 1$ ratio. After the top layer solidified at room temperature (30 minutes), the plates were transferred to the $37^{\circ} \mathrm{C}$ cell culture incubator and incubated for 14-21 days. During the incubation period, the cells were fed with $2 \mathrm{ml}$ of normal growing media twice a week. When the colonies were formed, the plates were stained with $1 \mathrm{ml}$ of $0.005 \%$ crystal violet for 1 hour. Then colonies were count and representative pictures for each cell line variant taken.

Matrigel 3D growth assay. The integrin $\alpha 6 \beta 1$-dependent 3D assay was performed as described previously [31] with further modifications. First, the matrigel was warmed up at $37^{\circ} \mathrm{C}$ and then $300 \mu \mathrm{l}$ added to each well of 24 -well plate. The plate was then placed into the hood for 2 hours till the matrigel solidified. Then, 20x10 $\mathrm{Fn} 14$ isogenic variants of H460 cells suspended in $1 \mathrm{ml}$ of normal growing media were plated on the matrigel. The plate was then incubated in cell culture incubator at $37^{\circ} \mathrm{C}, 5 \% \mathrm{CO}_{2}$. After $24-48$ hours the microscopic pictures were taken and results evaluated.

Establishment of tumor xenografts. $10 \times 10^{6} \mathrm{H} 460$ cell line variants (LacZ, cDNA, shRNA) were suspended in $0.1 \mathrm{ml}$ of sterile PBS and injected subcutaneously in the rear leg of male SCID mice. The mice were obtained from the University of Arizona Cancer Center SCID house colony at the age of 9 weeks with weight average of 20 grams. Tumor diameters measured twice weekly at right angles $\left(\mathrm{d}_{\text {short }}\right.$ and $\mathrm{d}_{\text {long }}$ ) using electronic calipers were converted to volume by the formula, volume $=$ $\left(\mathrm{d}_{\text {short }}\right)^{2} \mathrm{x}\left(\mathrm{d}_{\text {long }}\right) / 2$. Individual mice were sacrificed when the tumor volume reached $2000 \mathrm{~mm}^{3}$ and the tumors were harvested ( $1 / 2$ of tumor snap frozen and other $1 / 2$ fixed in NBF).

This study was performed in accordance with the recommendations in the Guide for the Care and Use of Laboratory Animals of the National Institutes of Health. The IACUC protocol was approved by the University of Arizona Institutional Animal Care and Use Committee (Permit number 07-029). All procedures were performed to make every effort to minimize suffering.

Immunohistochemistry. After all SCID mice from both groups of our xenograft model (mice injected with $\mathrm{H} 460$ cells over-expressing Fn14 and mice injected with H460 cells with silenced Fn14) were sacrificed, tumor samples from each mice were obtained and fixed in NBF. Samples were stained with hematoxylin and eosin and a serial section was stained for Fn14, integrin a 6 and PECAM using fluorescence immunohistochemistry with P4A8 (Biogen Idec, Inc., Cambridge, MA), AA6a (kindly provided by Dr. Cress, University of Arizona, Tucson, AZ) and PECAM (CD31) (BioLegend, San Diego, CA) antibodies respectively since we predicted that invading H460 cells over-expressing Fn14 will show most likely highest integrin a 6 expression. Fn 14 monoclonal antibody P4A8 was generated in an Fn 14 knockout mouse [32] immunized with Fn14-mychis recombinant protein. Anti-Fn14 monoclonal antibodies were screened and selected for binding to Fn14-positive cell lines. Immunohistochemistry was done as previously described using $2.5 \mathrm{Ag} / \mathrm{mL}$ of the P4A8 antibody [17]. To visualize vascularization within tumor samples, serial sections were stained with PECAM (CD31) commonly used as an endothelial (vascular) cell marker. Co-localization of the proteins in tumor cells was visualized using quantum dot-based fluorescence detection with a fluorescence microscope through the Tissue Acquisition and Molecular Analysis Shared Service at the UA Cancer Center. A scoring system for chromophore was used to capture the outcome: 0 , negative; 1 , weak; 2 , moderate; 3 , strong staining.

Statistical analysis. Data were collected and analyzed to obtain the mean and S.E.M for three independent experiments. Statistical significance between any two groups was determined by the two-tailed Student's t-test using Microsoft Excel, $\mathrm{P}$ values less than 0.05 were considered to be significant.

\section{Results}

Expression levels of Fn14 in cancer cells. Enhanced Fn14 expression levels are often found in various tumors and cancer cell lines. Quantitative real time PCR (RTPCR) analysis (Fig. 1A) confirmed up-regulation of Fn14 in several cancer cell lines including breast, prostate, colorectal, esophageal and NSCLC cells. Overall, the data indicate that Fn14 is expressed in all sixteen NSCLC cell lines with lower expression in H1155, H838, H1993, HCC15 and A549 cells, intermediate expression in H2122, H1975, H1792, H1568, H460, H1373, HCC193, HCC515, HCC461 and HCC44 cells and high expression in H226 cells (Fig. 1B).

From the panel of sixteen NSCLC cell lines, we have chosen $\mathrm{H} 460$ cells with intermediate levels of Fn 14 as a model to study the function of Fn14 in non-small lung carcinoma since H460 cells were never used before to investigate the functional role of Fn14 lung adenocarcinoma. To do so, we created H460 isogenic variants with altered Fn14 expression. As shown in Fig. 2, mRNA expression levels of Fn14 (Fig. 2A) and Fn14 protein levels (Fig. 2B) were stably altered in $\mathrm{H} 460$ cells relative to control by lentiviral transduction of Fn 14 cDNA or shRNA 


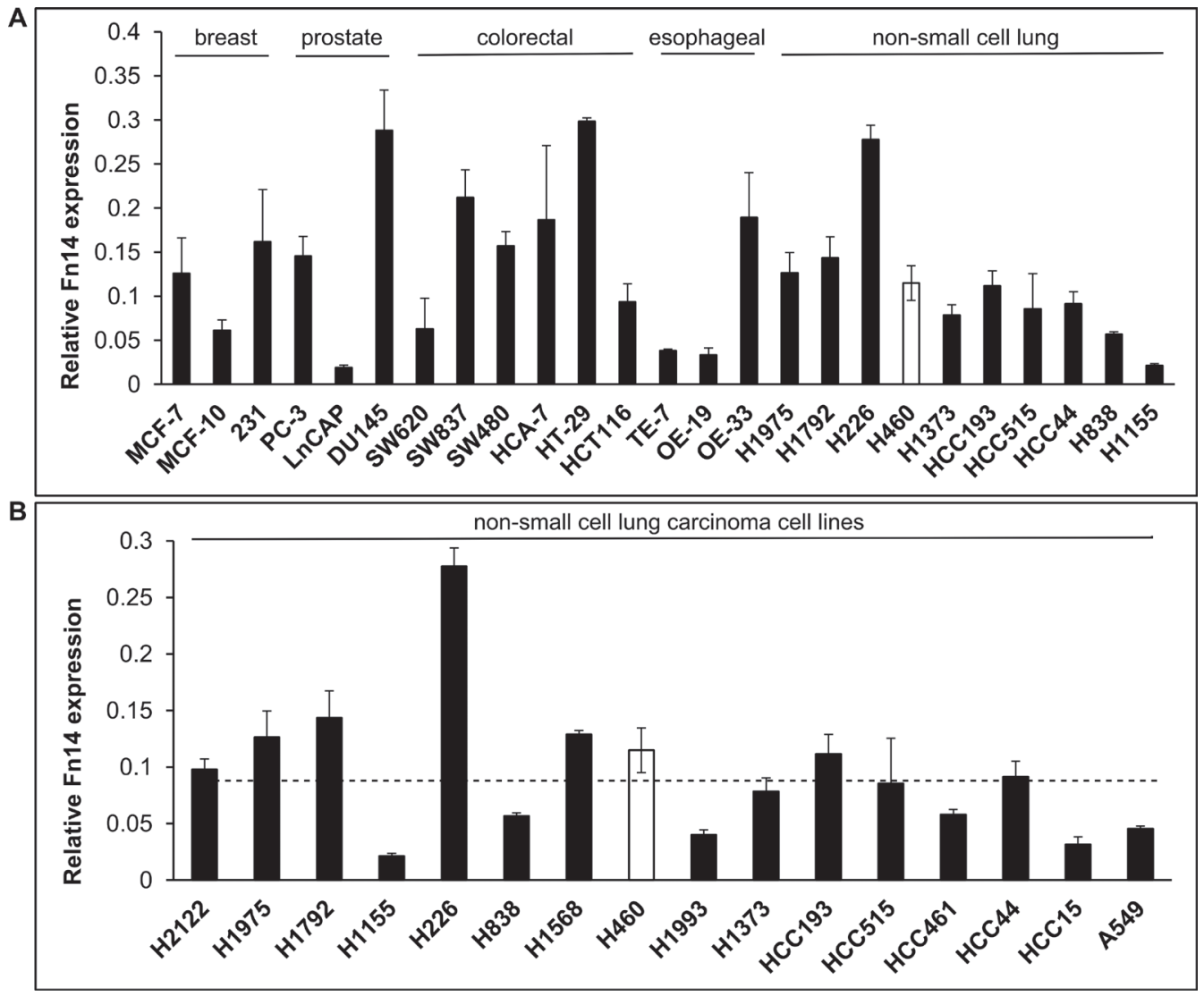

Figure 1. mRNA expression levels of Fn14 are elevated in various tumor cell lines. A) RT-PCR analysis of mRNA expression levels of Fn14 in breast, prostate, colorectal, esophageal and lung tumor cell lines. B) RT-PCR analysis of Fn14 expression in a panel of non-small cell lung carcinoma cells. Average Fn14 mRNA expression is shown with standard error bars. Averages represent Ct values after adjustment to GAPDH and are the result of a minimum of three independent replicates.

A

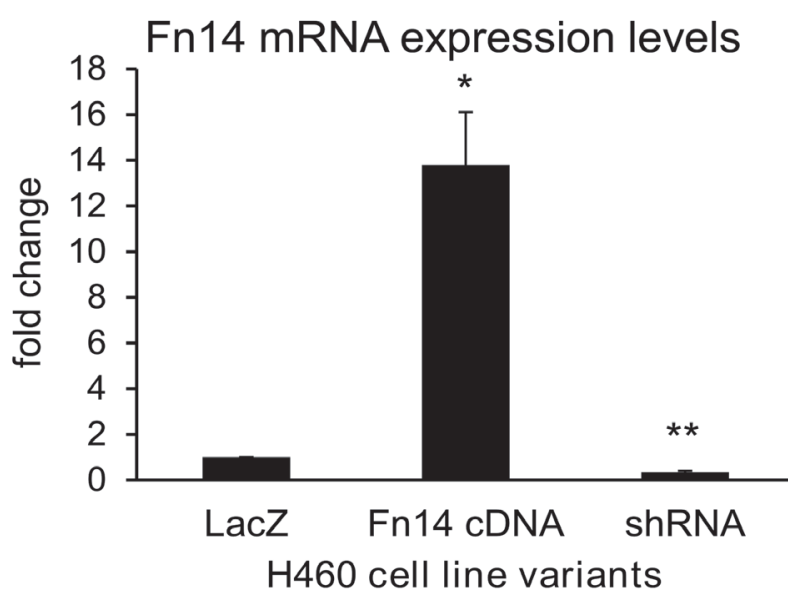

B

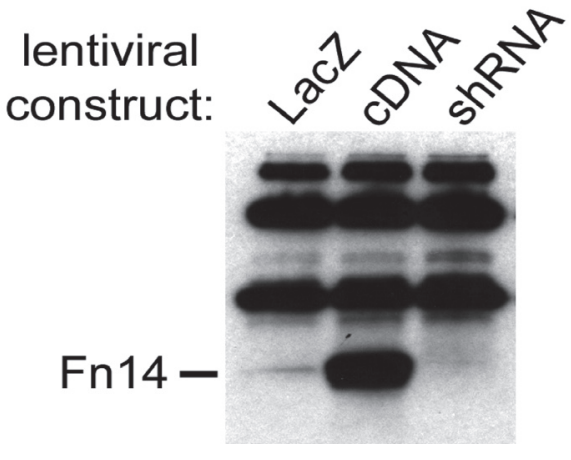

Figure 2. Fn14 expression is increased in NSCLC H460 cells produced by lentiviral infection with an Fn14 cDNA expression construct and decreased in cells produced by infection with a construct expressing shRNA targeting Fn14 mRNA. RT-PCR and Western blot confirmation of altered Fn14 expression in $\mathrm{H} 460$ cell line variants. A) Average Fn 14 mRNA expression is shown with standard error bars. Asterisks indicate: ${ }^{\star} \mathrm{p}<0.01$; ${ }^{\star \star} \mathrm{p}<0.001$ (two-tailed unpaired Student's T-test). Averages represent Ct values after adjustment to GAPDH and are the result of a minimum of three independent replicates. B) The band representing Fn14 protein is indicated, extraneous bands represent the heavy and light chains of the antibody used to immune-precipitate Fn14. 
A

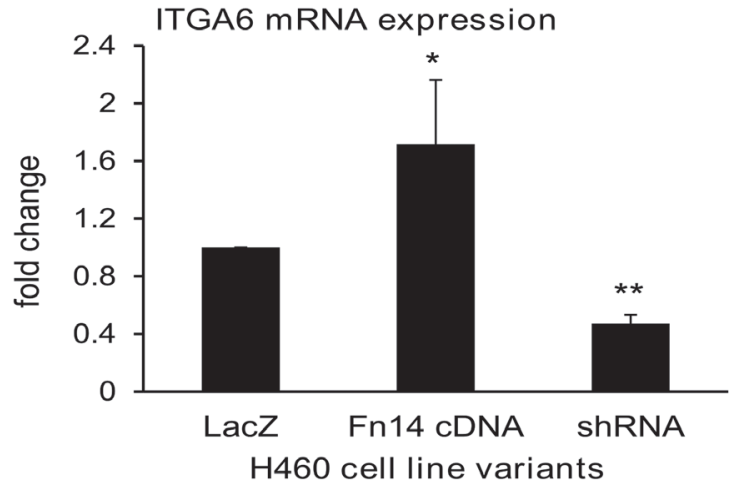

B

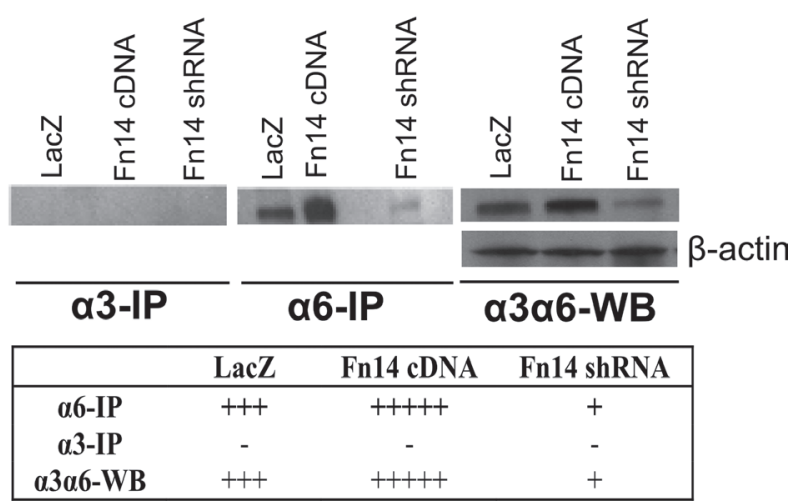

Figure 3. Fn 14 induces expression of integrin $a 6$. A) RT-PCR analysis of mRNA levels of integrin $\alpha 6$ in Fn 14 isogenic variants of H460 cells. Integrin a6 (ITGA6) expression was normalized to GAPDH control. The results are obtained from a minimum of three independent experiments. Asterisks indicate: ${ }^{\star} p<0.05 ;{ }^{* *} p<0.0005$ (two-tailed unpaired Student's T-test). B) Immuno-precipitation using anti- $\alpha 3$ antibody showing that none of the H460 variants with altered Fn 14 expression produced integrin $\alpha 3$ protein. Immuno-precipitation using anti- $\alpha 6$ antibody and western blot analysis (using AA6a antibody) of cell lysates of $\mathrm{H} 460$ isogenic variants showing increased levels of integrin a6 in cells over-expressing Fn14.
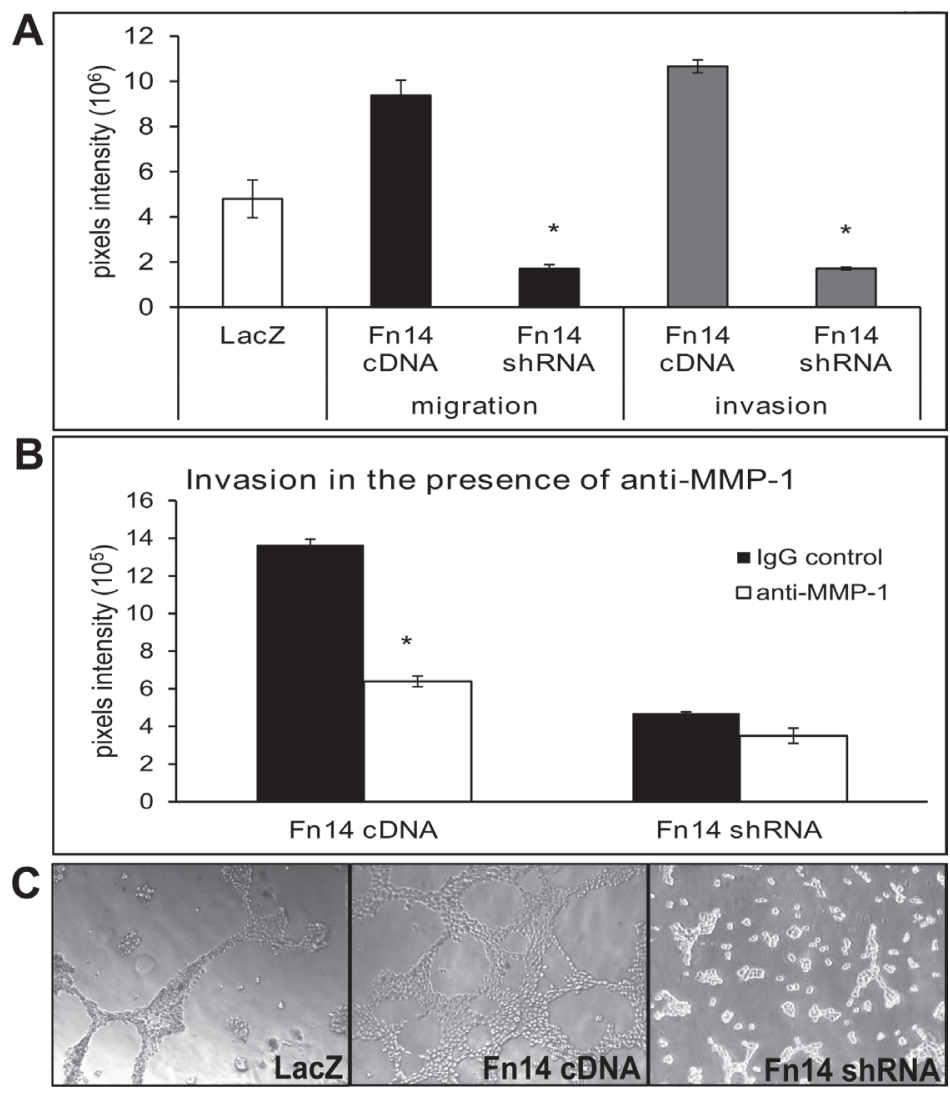

Figure 4. Expression of Fn14 affects H460 tumor cell migration and invasion. A) High expression levels of Fn14 increased cell migration through uncoated transwells as well as invasion through matrigel coated inserts, while loss of expression decreased migration relative to control cells. The data are shown as pixel intensities of cells invaded through the uncoated insert or matrigel with standard error bars and are the result of at least three independent experiments. Asterisk indicate $\mathbf{p}<\mathbf{0 . 0 1}$ (two-tailed unpaired Student's T-test). B) Invasion of $\mathrm{H} 460$ cells expressing high levels of Fn 14 was significantly decreased in the presence of $5 \mu \mathrm{M}$ anti-MMP-1 antibody while invasion of $\mathrm{H} 460$ cells with low Fn14 expression was not affected by antiMMP-1 functional blocking antibody. The data are shown as pixel intensities of cells that invaded through the matrigel with standard error bars and are the result of at least three independent experiments. Asterisk indicate $\mathbf{p}<\mathbf{0 . 0 1}$ (two-tailed unpaired Student's T-test) relative to IgG treated cells. C) Fn14 over-expressing cells had made integrin alpha 6-dependent anastomosing structures while Fn14-silnced cells were largely unorganized. The data are shown as representative microscopic pictures from at least three independent experiments. 
targeted against Fn14 mRNA. A variant in which LacZ was transduced served as a control for lentiviral transduction and confirmed that viral transduction and blasticidin selection had no effect on Fn14 expression.

Expression profile of integrin $a 6$ in isogenic variants of H460. Numerous studies have implicated $\alpha 6$ integrin in cancer progression [33]. However, there is still little knowledge about the interactions between Fn14 and this integrin known for its potential role in facilitating cancer cell motility and metastases. Expression analysis using RTPCR revealed increased expression of integrin a6 in H460 cells with high Fn14 expression compared to the cells with low Fn14 expression (Fig. 3A). To evaluate protein levels of integrin a6 on the surface of H460 tumor cells producing various levels of Fn14, we have used AA6a rabbit polyclonal anti-a6 integrin antibody greatly provided by Dr. Cress from the University of Arizona [27]. This antibody is suitable for non-specific western blot detection of integrin $\alpha 3$ as well as integrin $\alpha 6$. Western blot analysis of all Fn14 H460 cell line variants showed high levels of this integrin combination ( $\alpha 3$ and $\alpha 6$ ) in H460 cells over-expressing Fn14 and negligible levels in cells with silenced Fn14 expression (Fig. 3B). In effort to specifically detect the levels of integrin a6, we have precipitated a 3 integrin from cell lysates of all isogenic variants of H460 cells using commercially available mouse monoclonal anti-integrin $\alpha 3$, clone P1B5, antibody and then AA6 antibody (detecting both integrin $\alpha 3$ and $a 6$ ) was used for western blot analysis. Obtained data showed that neither of Fn14 isogenic variants expressed integrin a 3 suggesting that data obtained from western blot analysis of cell lysates can be linked directly to the expression levels of integrin a6. To confirm this observation, we have used rat monoclonal anti-integrin $\alpha 6$ antibody, clone J1B5, kindly provided by Dr. Cress [27] to immuno-precipitate integrin $a 6$ from cell lysates of H460 cell line variants expressing various levels of Fn14. Then, AA6 antibody was used for western blot detection of this integrin in these samples. As documented by Fig. 3B, increased levels of Fn14 were able to induce the expression of integrin a 6 protein in $\mathrm{H} 460$ cells.

Fn14-driven tumor cell motility is MMP-1 and integrin a6 dependent. One of the behaviors of cells that are associated with tumors is their ability to migrate and invade. To examine whether the H460 cells over-expressing Fn14 would be associated with higher levels of cellular migration and invasiveness compared to H460 cells expressing very low levels of Fn14. We conducted transwell migration and invasion assays to determine the migratory and invasive potential of $\mathrm{H} 460$ cells with various Fn14 levels. Cells expressing high levels of Fn14 demonstrated significantly increased tumor cell migration through uncoated transwell inserts as well as invasion through matrigel coated inserts (Fig. 4A) compared to cells expressing very low levels of Fn14. Since Fn14 is a receptor, we next tested if increased migration was ligand-dependent by addition of the Fn14-specific ligand TWEAK. Addition of TWEAK did appear to increase cell migration, but with no significance between all Fn14 isogenic variants (data not shown). In addition, the invasion through matrigel was MMP-1-dependent since anti-MMP-1 blocking antibody significantly decreased tumor cell invasion of H460 cells expressing high levels of Fn14 but had no significant effect on H460 cells with knocked down Fn14 expression (Fig. 4B).

Given the role integrins play in cell migration and based on the results we achieved by examining tumor cell invasion on a matrigel surface, we have hypothesized that integrin $a 6$ may explain Fn14-driven tumor cell invasion. To measure the requirement for integrin $a 6$ in NSCLC tumor cell invasion, we used a 3-dimensional matrigel matrix to evaluate the formation of integrin a6-dependent anastomosing structures in H460 cells with altered Fn14 expression. As shown in Fig. 4C, cells with forced Fn14 expression formed anastomosing structures on the matrigel surface, while Fn14-silenced cells did not.

The role of Fn14 in an in vitro and in vivo tumor formation and metastases. Activation of NF- $\kappa$ B and Rac1 by Fn 14 may have effects on cellular phenotype beyond migration and invasion. To test additional changes in tumor cell behavior, we compared the H460 variants' capacity for self-renewal in a soft agar colony formation assay. We have observed significantly increased number of colonies formed by H460 cells expressing high levels of Fn14 relative to cells with silenced Fn14 (Fig. 5).
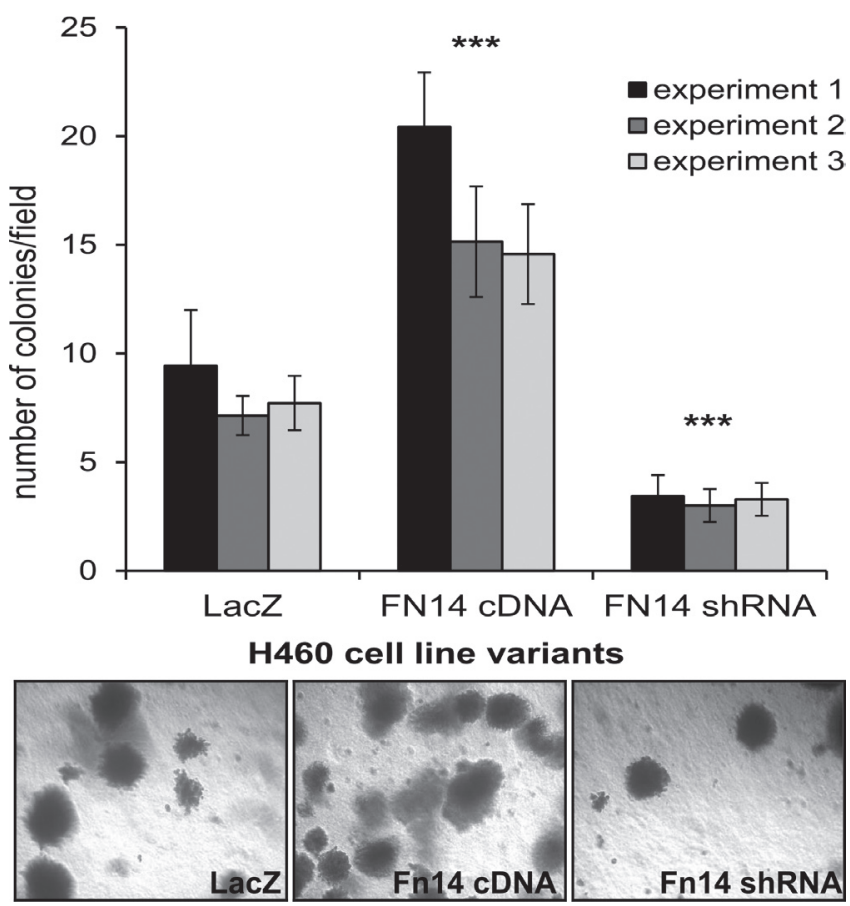

Figure 5. In vitro colony formation was increased in cells expressing high levels of Fn14. H460 cells with low Fn14 expression (Fn14 shRNA) form significantly fewer colonies than $\mathrm{H} 460$ cells with high Fn14 expression (Fn14 cDNA), while control cells with endogenous Fn14 expression display intermediate colony forming ability (LacZ). Colony formation was tested in three independent experiments for each cell line variant; average colonies/ field are shown; error bars, standard deviation; a two-tailed t-test with variances assumed equal was performed on the three cell lines within each experiment, all nine statistical tests yielded a $\mathrm{p}<0.001$. 
To establish the role of Fn14 in an in vivo tumor formation and metastases, we evaluated the effect of Fn 14 and integrin $a 6$ on tumor growth in a SCID mouse tumor xenograft model. We observed significantly larger tumors in the group of mice injected with H460 cells expressing high levels of Fn14 compared to the group of mice injected with cells expressing low Fn14 levels (Fig. 6A). Mouse xenograft model for NSCLC tumor cell migration, invasion and angiogenesis was carried out long enough for potential metastases to occur. Since, integrin $\alpha 6 \beta 1$ heterodimer is known for its role in tumor cell migration and metastatic processes; we sought to evaluate the tumors generated from H460 cells expressing various levels of Fn14. Our data show a striking difference in tumor cell motility between the cells with altered Fn14 levels. Moreover, increased levels of integrin $a 6$ were detected using immunohistochemistry in tumors from the mice injected with $\mathrm{H} 460$ cells over-expressing Fn14 compared to low levels of integrin $a 6$ in tumors generated from $\mathrm{H} 460$ cells with knocked down expression of Fn14. Metastases in lungs, liver and lymph nodes (Fig. 6B) were found in mice initially injected with H460 tumor cells over-

A

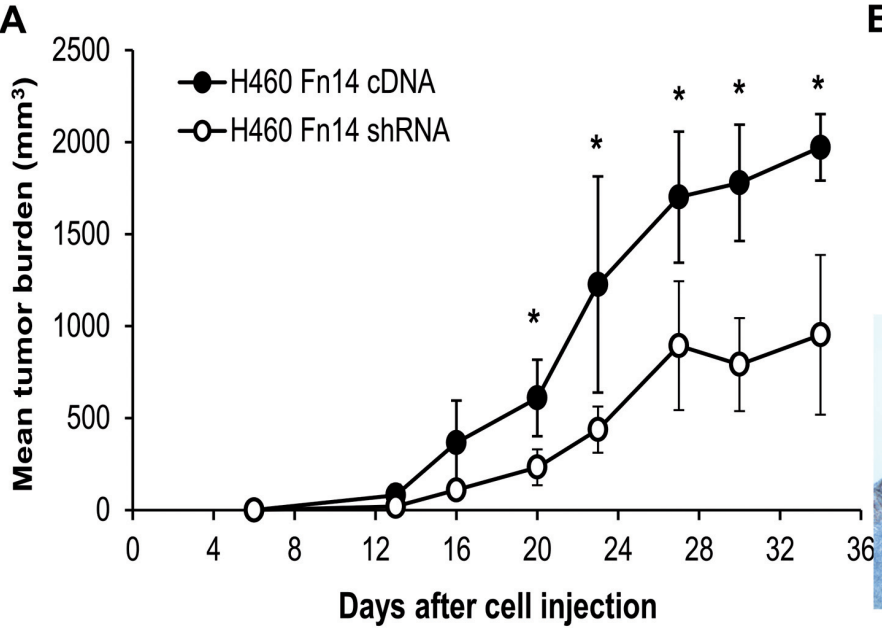

C

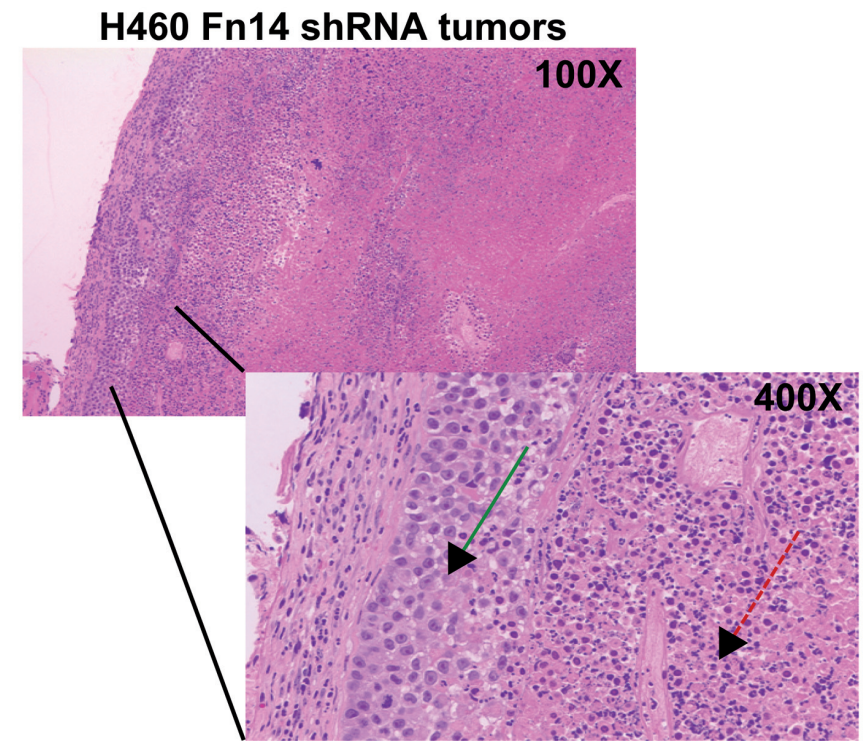

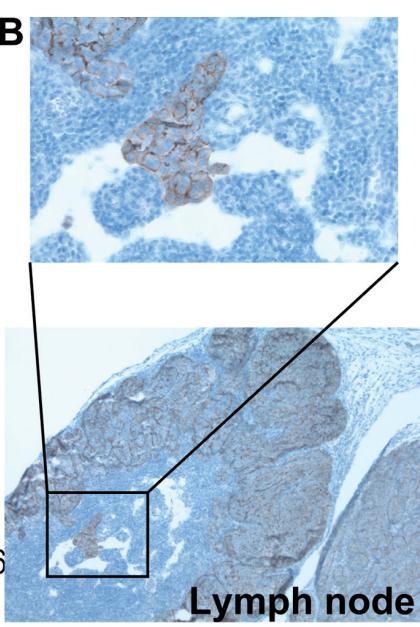

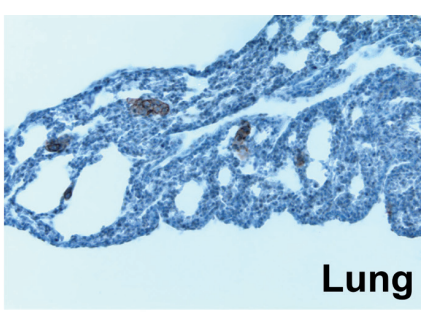

D
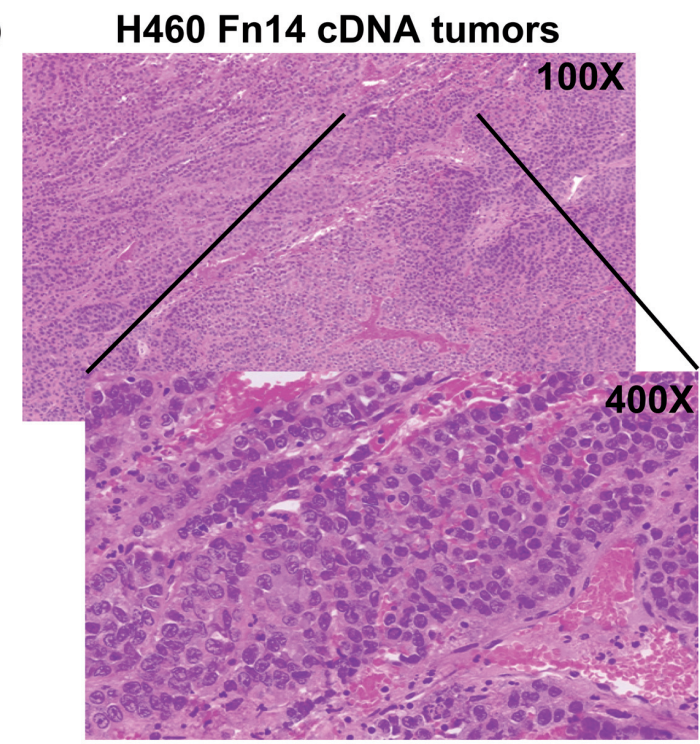

Figure 6. Fn 14 expression regulates the in vivo tumor growth of H460 NSCLC cells. A) Ten million H460 cells with altered Fn14 expression was injected subcutaneously into the flanks of four SCID mice per variant. Twenty days after cell injection, mice injected with H460 Fn14 cDNA cells (higher Fn14 expression) showed significantly increased tumor growth than H460 shRNA cells (low Fn14 expression). The data represent a mean tumor burden with standard error bars and asterisk indicates $\mathbf{p}<\mathbf{0 . 0 5}$ (two-tailed unpaired Student's T-test). B) No tumor cells were observed migrating in xenograft tumors from Fn14-silenced cells while clusters of cells were frequently seen migrating in tumors from Fn14-expressing cells. Immunohistochemistry for integrin a 6 from serial sections of Fn14 over-expressing tumor showed that tumor cells have invaded into the lymph nodes, liver and lungs of mice that were injected subcutaneously with $\mathrm{H} 460$ cells over-expressing Fn14. H\&E stain showing bulk C) Fn14 shRNA - green arrow shows the viable cells on periphery of the tumor while the red arrow indicated the necrotic cells inside of the tumor; and D) Fn14 cDNA tumors, higher magnification view, objective lens magnification is indicated. 
expressing Fn14 compared to mice initially injected with $\mathrm{H} 460$ tumor cells expressing very low levels of Fn14. This dramatic difference in tumor cell motility confirmed our in vitro data and indicates the ability to create in vivo model for NSCLC migration, invasion and metastases. Furthermore, the tumors produced in mice injected with $\mathrm{H} 460$ tumor cells expressing very low levels of Fn 14 were significantly smaller and necrotic with viable cells only on the periphery of the tumor (Fig. 6C) and contained significantly fewer blood vessels while tumors from mice injected with cells over-expressing Fn14 were larger, less necrotic with viable cells throughout the tumor (Fig. 6D) and showed more vasculature (Supplemental Fig. 1A). Moreover, the Fn14 was able to significantly increase the expression of well-known angiogenic factor IL-8 (Supplemental Figure 1B).

\section{Discussion}

In this study, we explored the functional role of Fn14 in lung adenocarcinoma using H460 cell line as a model. We determined that Fn 14 facilitates in vitro tumor cell migration, invasion, and colony forming by up-regulation of integrin a6 $\beta 1$ and MMP-1. Moreover, we document the ability of Fn14 to facilitate in vivo tumor formation, angiogenesis, and metastases.

Fn14 (TNFRSF12A) is known as a member of the tumor necrosis factor super-family of cell surface receptors capable of regulating proliferation, cellular adhesion and migration, invasion, apoptosis, differentiation and survival $[3,13,34]$. Previously, it was documented that high expression of Fn14 receptor in primary breast tumors from patients who did not received chemotherapy correlated strongly with metastases. On the other hand, low Fn14 expression correlated with lymph node-negative disease and well differentiated tumors, what is indicative of good prognosis [15]. Another group reported that in breast adenocarcinomas, certain proteins including Fn14 associated with the endoplasmic reticulum stress phenotype are candidate markers of brain metastases [35]. Recently, it was suggested that Fn 14 protein is a valuable marker of breast carcinoma progression and might be a good prognostic marker for breast carcinoma patients [23]. Moreover, Asrani et al. recently reported that Fn14 is able to promote breast cancer cell migration, invasion and MMP-9 expression [36]. Huang et al. reported that Fn14 over-expression promotes androgenindependent prostate cancer progression what correlates with poor treatment outcomes [22]. Lastly, another group found increased expression of Fn14 in histological sections of human prostate adenocarcinoma and two human prostate cancer cell lines with higher expression in the androgen-independent PC-3 cells relative to androgen-sensitive LNCaP prostate cancer cells [37]. These observations confirm our findings of higher Fn14 expression in DU145 and PC-3 prostate cancer cells relative to lower expression in LNCaP cells. Higher Fn14 expression was also documented in human endometrial cancer specimens compared with that in normal endometrial specimens [34]. Gu et al. recently found expression of Fn 14 in human malignant ovarian tumors, but not in normal ovarian tissues or benign epithelial ovarian tumors. Moreover, they suggested that Fn14 could act as ovarian tumor suppressor through the activation of macrophages and can be detected as a malignant ovarian tumor marker [21]. The functional importance of Fn14/TWEAK pathway was demonstrated in pancreatic cancer progression by showing a significant inhibition of tumor cell growth after anti-Fn14 blocking antibody treatment in vitro as well as in vivo using a murine gastrointestinal cancer model [19]. Fn14 was found to be overexpressed in gastric tumor tissues compared to normal tissue; and altered Fn14 expression levels affected gastric cancer cellular growth and were correlated with survival of patients with gastric cancer [38]. Furthermore, Fn14 expression was detected in $\sim 60 \%$ of tested melanoma cell lines. Fn 14 expression was low in normal skin, but elevated in $93 \%$ of primary melanoma specimens and in $58 \%$ of melanoma metastases tested suggesting Fn14 as a therapeutic target in melanoma [39]. Heterogeneously expressed Fn14 in cancerous and noncancerous structures correlates negatively with the grade and survival of renal cell carcinoma patients [40]. Fn14 was also found to be over-expressed in migrating glioma cells in vitro and in glioblastoma clinical specimens in vivo suggesting that targeted therapy against Fn14 as an adjuvant to surgery may improve management of invasive glioma cells and advance the outcome of this devastating cancer [41]. Moreover, both TWEAK and its receptor Fn14 were increased in neuroblastoma cell lines and high-stage primary tumors and found to function as important regulators of primary neuroblastoma growth, invasion and survival [42]. There is only one report which is showing that there are elevated expression levels of Fn14 in non-small cell lung cancer correlated with activated EGFR that can promote NSCLC cell migration and invasion [3]. However, there are still missing information about a functional role of Fn14 and mechanism of lung adenocarcinoma motility.

To study a functional role of Fn14 in NSCLC, we have created three isogenic cell line variants with altered Fn14 expression: H460 cells over-expressing Fn14 (Fn14cDNA), cells with silenced Fn14 expression (shRNA) and LacZ cells as a control for lentiviral production. Using these isogenic variants, we determined that suppressed/increased expression of Fn14 in tumor cells affects their capacity for migration in a TWEAK independent manner. We have found that the higher the expression of Fn14 within the NSCLC cells is, the more advanced the migratory abilities are observed. These observations correlate with similar findings of Whitsett et al. who found that Fn14 depletion reduced in vitro migration and invasive capacity of HCC 827 and H1975 NSCLC cell lines. The ectopic expression of Fn14 in A549 NSCLC cells enhanced their migratory abilities approximately 2 -fold [3].

Integrins are important for facilitating cellular adhesion, motility and metastases. However, there is only limited information available about the specific interactions between 
Fn14 and integrins that might be involved in cancer cell motility and metastases. It has been previously shown that expression-correlated set of genes including Fn14 and integrin $\beta 1$ functions in molecular interaction networks promoting cellular migration via structural changes and signaling [26]. There is an evidence of $\alpha 6 \beta 1$ involvement in migration and invasiveness of various tumor cells. For example, a6 $\beta 1$ is implicated in glioblastoma cell migration, invasiveness and glioma progression [43]. This integrin is also known to mediate adhesion and migration of highly invasive and metastatic breast carcinomas [44], hepatoma cells [45] and pancreatic carcinoma [46]. Other studies indicate that $\alpha 6 \beta 1$ and $\alpha 3 \beta 1$ are maintained in the majority of prostate carcinomas and remain associated with invasive carcinoma, the latter being predominant $[47,48]$. Moreover, a potential role for integrin a6 $\beta 1$ in directing prostate tumor cell invasion on nerves during perineural invasion was suggested [49]. Our present study reports for the first time the interactions between Fn14 levels and integrin a6 $\beta 1$ necessary to promote the migration and invasion of non-small cell lung carcinoma using a H460 cells. Obtained data suggest that Fn14 can alter the in vitro and in vivo motile characteristics of non-small cell lung carcinoma $\mathrm{H} 460$ cells in a a $6 \beta 1$ dependent manner.

Integrin $a 6 \beta 1$ is known to be involved in matrigel morphogenesis and cell spreading [31]. When cells are plated on basement membrane matrix (matrigel), collagen, or other substrates, they often form integrin a6-dependent anastomosing cellular network, which is an in vitro model of angiogenesis and tumor cell invasion [31]. In our study, we used formation of a6-dependent structures to measure the requirement for integrin $a 6$ induced by Fn14 in NSCLC tumor cell invasion. H460 cells over-expressing Fn14 formed anastomosing structures on the matrigel surface, while Fn14-silenced cells did not. Thus, this is a first report of adhesion strengthening a6-dependent cords on matrigel induced by Fn14.

Furthermore, we showed that increased levels of Fn14 induced two other well-known targets of NF- $\kappa \mathrm{B}$ signaling pathway, integrin $a 6$ and matrix metalloprotease 1 (MMP-1). However, whether the induction of integrin $a 6$ and MMP-1 by Fn14 is responsible for increased NSCLC tumor cell migration and invasion has not been studied yet. Integrin $a 6$ is expressed on the cell surface as a hetero-dimer with integrin $\beta 1$. Integrin $\alpha 6 \beta 1$ is the receptor for laminin and involved in tumor cell migration [47]. In our tumor xenograft model, we observed increased invasiveness of NSCLC cells expressing Fn14 mediated through the integrin a6. The cells invaded through membranes, including those lining lymph vessels, lungs and liver. This invasive phenotype requires migration, but also the ability to degrade the extracellular matrix that constitutes membranes. MMP-1 is a secreted protein that functions to degrade collagen in the extra-cellular matrix and is associated with tumor cell invasion [50]. Our in vitro data indicate involvement of MMP-1 in invasiveness of $\mathrm{H} 460$ cells over-expressing Fn14 since we observed a striking difference in invasive capabilities of these cells that showed significantly higher invasion to the lymph vessels, lungs and liver while Fn14-silenced cells failed to invade surrounding tissue. Previously, it was shown that MMP-1 expression is associated with poor prognosis in esophageal adenocarcinoma [51]. Recently, it was shown that the high plasma levels of MMP-1 were associated with advanced-stage of lung cancer and significantly lower overall survival rate of these patients. MMP-1 protein was found to be extraordinarily over-expressed in tumor tissues of lung cancer patients and was associated with the cancer progression including tumor size, staging and lymphatic invasion in patients suffering from lung cancers [52].

In a summary, we report for the first time a functional role of altered Fn14 expression in non-small cell lung carcinoma H460 cells. We demonstrate that increased expression of Fn 14 is associated with tumor cell migration, invasion, angiogenesis, tumor formation and metastases. NSCLC tumor cells expressing high levels of Fn14 showed increased in vitro migration through uncoated transwell inserts. Moreover, increased levels of Fn14 correlate with enhanced in vitro tumor cell invasion through the matrigel in an MMP-1-dependent manner. Fn14 was able to induce expression of integrin $a 6$ what is suggestive of a novel mechanism of lung carcinoma migration and invasion through $\alpha 6 \beta 1-F n 14$ interactions. Thus, this research may be a step toward developing improved treatment strategies for non-small cell lung cancer by improved detection and inhibition of metastasis.

Supplementary information is available in the online version of the paper.

Acknowledgements: We would like to thank Dr. Anne Cress for providing anti- $\alpha 6$ integrin antibody clone J1B5 and AA6a antibody for Western blot and IHC analyses. We also thank Dr. Janda for his valuable insights, critique of the manuscript and his assistance in preparing this manuscript. Immunohistochemistry was performed by the university of Arizona Cancer Center's Tissue Acquisition Cellular/ Molecular Analysis Shared Service; RTPCR data were generated by the University of Arizona Cancer Center Genomics Shared Service; and mouse xenograft experiments were performed by the University of Arizona Experimental Mouse Shared Service; all services are supported by NCI grant 5P30CA023074. This work was support by the NCI CA023074-26 and a pilot grant to GW (ES06694).

\section{References}

[1] BRAY F, SANKILA R, FERLAY J, PARKIN DM Estimates of cancer incidence and mortality in Europe in 1995. Eur J Cancer 2002; 38: 99-166. http://dx.doi.org/10.1016/S09598049(01)00350-1

[2] HOFFMAN PC, MAUER AM, VOKES EE Lung cancer. Lancet 2000; 355: 479-485. http://dx.doi.org/10.1016/S01406736(00)82038-3

[3] WHITSETT TG, CHENG E, INGE L, ASRANI K, JAMESON $\mathrm{NM}$ et al. Elevated Expression of Fn14 in Non-Small Cell Lung Cancer Correlates with Activated EGFR and Promotes Tumor Cell Migration and Invasion. American Journal of 
Pathology 2012; 181: 111-120. http://dx.doi.org/10.1016/j. ajpath.2012.03.026

[4] YANO T, MIURA N, TAKENAKA T, HARO A, OKAZAKI H et al. Never-smoking nonsmall cell lung cancer as a separate entity - Clinicopathologic features and survival. Cancer 2008; 113: 1012-1018. http://dx.doi.org/10.1002/cncr.23679

[5] AMERICAN CANCER SOCIETY. American Cancer Society: New York 2008; pp v.

[6] BOFFETTA P Epidemiology of environmental and occupational cancer. Oncogene 2004; 23: 6392-6403. http://dx.doi. org/10.1038/sj.onc. 1207715

[7] BOFFETTA P Human cancer from environmental pollutants: The epidemiological evidence. Mutation Research-Genetic Toxicology and Environmental Mutagenesis 2006; 608: 157-162. http://dx.doi.org/10.1016/j.mrgentox.2006.02.015

[8] FERRECCIO C, SANCHA AM Arsenic exposure and its impact on health in Chile. Journal of Health Population and Nutrition 2006; 24: 164-175.

[9] MINNA JD, ROTH JA, GAZDAR AF Focus on lung cancer. Cancer Cell 2002; 1: 49-52. http://dx.doi.org/10.1016/S15356108(02)00027-2

[10] WINKLES JA The TWEAK - Fn14 cytokine-receptor axis: discovery, biology and therapeutic targeting. Nature Reviews Drug Discovery 2008; 7: 411-425. http://dx.doi.org/10.1038/ $\operatorname{nrd} 2488$

[11] ZHU LX, ZHANG HH, MEI YF, ZHAO YP, ZHANG ZY Role of tumor necrosis factor-like weak inducer of apoptosis (TWEAK)/fibroblast growth factor-inducible 14 (Fn14) axis in rheumatic diseases. Chinese Medical Journal 2012; 125: 3898-3904.

[12] WILEY SR, WINKLES JA TWEAK, a member of the TNF superfamily, is a multifunctional cytokine that binds the TweakR/ Fn14 receptor. Cytokine \& Growth Factor Reviews 2003; 14: 241-249. http://dx.doi.org/10.1016/S1359-6101(03)00019-4

[13] MICHAELSON JS, BURKLY LC Therapeutic Targeting of TWEAK/Fn14 in Cancer: Exploiting the Intrinsic Tumor Cell Killing Capacity of the Pathway. Death Receptors and Cognate Ligands in Cancer 2009; 49: 145-160. http://dx.doi. org/10.1007/400 2008 18

[14] ZHOU H, MARKS JW, HITTELMAN WN, YAGITA H, CHEUNG LH et al. Development and Characterization of a Potent Immunoconjugate Targeting the Fn14 Receptor on Solid Tumor Cells. Molecular Cancer Therapeutics 2011; 10: 1276-1288. http://dx.doi.org/10.1158/1535-7163.MCT-11-0161

[15] WILLIS AL, TRAN NL, CHATIGNY JM, CHARLTON N, VU H et al. The fibroblast growth factor-inducible 14 receptor is highly expressed in HER2-positive breast tumors and regulates breast cancer cell invasive capacity. Molecular Cancer Research 2008; 6: 725-734. http://dx.doi.org/10.1158/15417786.MCR-08-0005

[16] FENG SL, GUO Y, FACTOR VM, THORGEIRSSON SS, BELL DW et al. The Fn14 immediate-early response gene is induced during liver regeneration and highly expressed in both human and murine hepatocellular carcinomas. Am J Pathol 2000; 156: 1253-1261. http://dx.doi.org/10.1016/S0002-9440(10)64996-6

[17] TRAN NL, MCDONOUGH WS, DONOHUE PJ, WINKLES JA, BERENS TJ et al. The human Fn14 receptor gene is up-regulated in migrating glioma cells in vitro and overexpressed in advanced glial tumors. American Journal of Pathology 2003; 162: 1313-1321. http://dx.doi.org/10.1016/ S0002-9440(10)63927-2

[18] TRAN NL, MCDONOUGH WS, SAVITCH BA, FORTIN SP, WINKLES JA et al. Increased fibroblast growth factorinducible 14 expression levels promote glioma cell invasion via Rac1 and nuclear factor-kappaB and correlate with poor patient outcome. Cancer Res 2006; 66: 9535-9542. http:// dx.doi.org/10.1158/0008-5472.CAN-06-0418

[19] YORIKI R, AKASHI S, SHO M, NOMI T, YAMATO I et al. Therapeutic potential of the TWEAK/Fn14 pathway in intractable gastrointestinal cancer. Experimental and Therapeutic Medicine 2011; 2: 103-108.

[20] SHIMADA K, FUJII T, TSUJIKAWA K, ANAI S, FUJIMOTO K et al. ALKBH3 contributes to survival and angiogenesis of human urothelial carcinoma cells through NADPH oxidase and tweak/ Fn14/VEGF signals. Clin Cancer Res 2012; 18: 5247-5255. http:// dx.doi.org/10.1158/1078-0432.CCR-12-0955

[21] GU LY, DAI L, CAO C, ZHU J, DING CW et al. Functional Expression of TWEAK and the Receptor Fn14 in Human Malignant Ovarian Tumors: Possible Implication for Ovarian Tumor Intervention. Plos One 2013; 8:

[22] HUANG MG, NARITA S, TSUCHIYA N, MA ZY, NUMAKURA K et al. Overexpression of Fn 14 promotes androgen-independent prostate cancer progression through MMP-9 and correlates with poor treatment outcome. Carcinogenesis 2011; 32: 1589-1596. http://dx.doi.org/10.1093/ carcin/bgr182

[23] WANG J, LIU Y, WEI MJ, MI XY, WANG EH Clinical correlations and prognostic relevance of Fn14 expression in breast carcinoma. Histol Histopathol 2013; 28: 859-864.

[24] CULP PA, CHOI D, ZHANG YK, YIN J, SETO P et al. Antibodies to TWEAK Receptor Inhibit Human Tumor Growth through Dual Mechanisms. Clinical Cancer Research 2010; 16: 497-508. http://dx.doi.org/10.1158/1078-0432.CCR-09$\underline{1929}$

[25] LEE JW, JULIANO R Mitogenic signal transduction by integrin- and growth factor receptor-mediated pathways. Mol Cells 2004; 17: 188-202.

[26] KOHN KW, ZEEBERG BR, REINHOLD WC, SUNSHINE $\mathrm{M}$, LUNA A et al. Gene expression profiles of the NCI-60 human tumor cell lines define molecular interaction networks governing cell migration processes. PLoS One 2012; 7: e35716. http://dx.doi.org/10.1371/journal.pone.0035716

[27] PAWAR SC, DEMETRIOU MC, NAGLE RB, BOWDEN GT, CRESS AE Integrin alpha6 cleavage: a novel modification to modulate cell migration. Exp Cell Res 2007; 313: 1080-1089. http://dx.doi.org/10.1016/j.yexcr.2007.01.006

[28] DAMSKY CH, LIBRACH C, LIM KH, FITZGERALD ML, MCMASTER MT et al. Integrin switching regulates normal trophoblast invasion. Development 1994; 120: 3657-3666.

[29] JANDOVA J, BEYER TE, MEUILLET EJ, WATTS GS The matrix protein CCN1/CYR61 is required for alpha nu beta(5)-mediated cancer cell migration. Cell Biochemistry and Function 2012; 30: 687-695. http://dx.doi.org/10.1002/ $\underline{\text { cbf. } 2853}$ 
[30] JANDOVA J, SHI MJ, NORMAN KG, STRICKLIN GP, SLIGH JE Somatic alterations in mitochondrial DNA produce changes in cell growth and metabolism supporting a tumorigenic phenotype. Biochimica Et Biophysica Acta-Molecular Basis of Disease 2012; 1822: 293-300. http://dx.doi.org/10.1016/j. bbadis.2011.11.010

[31] ZHANG XA, KAZAROV AR, YANG XW, BONTRAGER AL, STIPP CS et al. Function of the tetraspanin CD151-alpha 6 beta 1 integrin complex during cellular morphogenesis. Molecular Biology of the Cell 2002; 13: 1-11. http://dx.doi. org/10.1091/mbc.01-10-0481

[32] JAKUBOWSKI A, AMBROSE C, PARR M, LINCECUM JM, WANG MZ et al. TWEAK induces liver progenitor cell proliferation. Journal of Clinical Investigation 2005; 115: 2330-2340. http://dx.doi.org/10.1172/JCI23486

[33] MERCURIO AM, BACHELDER RE, RABINOVITZ I, O'CONNOR KL, TANI T et al. The metastatic odyssey: the integrin connection. Surg Oncol Clin N Am 2001; 10:313-328, viii-ix.

[34] WANG DF, FUNG JNT, TUO Y, HU LN, CHEN C TWEAK/ Fn14 promotes apoptosis of human endometrial cancer cells via caspase pathway. Cancer Letters 2010; 294: 91-100. http:// dx.doi.org/10.1016/j.canlet.2010.01.027

[35] SANZ-PAMPLONA R, ARAGUES R, DRIOUCH K, MARTIN B, OLIVA B et al. Expression of Endoplasmic Reticulum Stress Proteins Is a Candidate Marker of Brain Metastasis in both ErbB-2(+) and ErbB-2(-) Primary Breast Tumors. American Journal of Pathology 2011; 179: 564-579. http:// dx.doi.org/10.1016/j.ajpath.2011.04.037

[36] ASRANI K, KERI RA, GALISTEO R, BROWN SAN, MORGAN SJ et al. The HER2- and Heregulin beta 1 (HRG)-Inducible TNFR Superfamily Member Fn14 Promotes HRG-Driven Breast Cancer Cell Migration, Invasion, and MMP9 Expression. Molecular Cancer Research 2013; 11: 393-404. http://dx.doi. org/10.1158/1541-7786.MCR-12-0542

[37] SANZ AB, SANCHEZ-NINO MD, CARRASCO S, MANZARBEITIA F, RUIZ-ANDRES O et al. Inflammatory Cytokines and Survival Factors from Serum Modulate Tweak-Induced Apoptosis in PC-3 Prostate Cancer Cells. Plos One 2012; 7:

[38] KWON OH, PARK SJ, KANG TW, KIM M, KIM JH et al. Elevated fibroblast growth factor-inducible 14 expression promotes gastric cancer growth via nuclear factor-kappaB and is associated with poor patient outcome. Cancer Lett 2012; 314: 73-81. http://dx.doi.org/10.1016/j.canlet.2011.09.016

[39] ZHOU H, EKMEKCIOGLU S, MARKS JW, MOHANNEDALI KA, ASRANI K et al. The TWEAK Receptor Fn14 Is a Therapeutic Target in Melanoma: Immunotoxins Targeting Fn14 Receptor for Malignant Melanoma Treatment. Journal of Investigative Dermatology 2013; 133: 1052-1062. http:// dx.doi.org/10.1038/jid.2012.402

[40] PELEKANOU V, NOTAS G, THEOdOROPOULOU K, KAMPA M, TAKOS D et al. Detection of the TNFSF Members BAFF, APRIL, TWEAK and their Receptors in Normal Kidney and Renal Cell Carcinomas: Correlation with Clinical and Histological Development of the Disease. Journal of Pathology 2011; 224: S5-S5.
[41] TRAN NL, MCDONOUGH WS, SAVITCH BA, SAWYER TF, WINKLES JA et al. The tumor necrosis factor-like weak inducer of apoptosis (TWEAK)-fibroblast growth factorinducible 14 (Fn14) signaling system regulates glioma cell survival via NFkappaB pathway activation and BCL-XL/ BCL-W expression. J Biol Chem 2005; 280: 3483-3492. http:// dx.doi.org/10.1074/jbc.M409906200

[42] PETTERSEN I, BARYAWNO N, ABEL F, BAKKELUND WH, ZYKOVA SN et al. Expression of TWEAK/Fn14 in neuroblastoma: Implications in tumorigenesis. International Journal of Oncology 2013; 42: 1239-1248.

[43] DELAMARRE E, TABOUBI S, MATHIEU S, BERENGUER C, RIGOT V et al. Expression of Integrin alpha 6 beta 1 Enhances Tumorigenesis in Glioma Cells. American Journal of Pathology 2009; 175: 844-855. http://dx.doi.org/10.2353/ ajpath.2009.080920

[44] SHAW LM, CHAO C, WEWER UM, MERCURIO AM Function of the integrin alpha 6 beta 1 in metastatic breast carcinoma cells assessed by expression of a dominant negative receptor. Cancer Research 1996; 56: 959-963.

[45] DAI JY, DOU KF, WANG CH, ZHAO P, LAU WB et al. The interaction of HAb18G/CD147 with integrin alpha6beta1 and its implications for the invasion potential of human hepatoma cells. BMC Cancer 2009; 9: 337. http://dx.doi. org/10.1186/1471-2407-9-337

[46] SAWAI H, OKADA Y, FUNAHASHI H, MATSUO Y, TAKAHASHI $\mathrm{H}$ et al. Interleukin-1alpha enhances the aggressive behavior of pancreatic cancer cells by regulating the alpha6beta1-integrin and urokinase plasminogen activator receptor expression. BMC Cell Biol 2006; 7: 8. http://dx.doi. org/10.1186/1471-2121-7-8

[47] CRESS AE, RABINOVITZ I, ZHU W, NAGLE RB The alpha 6 beta 1 and alpha 6 beta 4 integrins in human prostate cancer progression. Cancer Metastasis Rev 1995; 14: 219-228. http:// dx.doi.org/10.1007/BF00690293

[48] KING TE, PAWAR SC, MAJUTA L, SROKA IC, WYNN D et al. The Role of Alpha 6 Integrin in Prostate Cancer Migration and Bone Pain in a Novel Xenograft Model. Plos One 2008; 3:

[49] SROKA IC, ANDERSON TA, MCDANIEL KM, NAGLE RB, GRETZER MB et al. The laminin binding integrin alpha6beta 1 in prostate cancer perineural invasion. J Cell Physiol 2010; 224: 283-288. http://dx.doi.org/10.1002/jcp.22149

[50] DERYUGINA EI, QUIGLEY JP Matrix metalloproteinases and tumor metastasis. Cancer Metastasis Rev 2006; 25: 9-34. http://dx.doi.org/10.1007/s10555-006-7886-9

[51] MORI M, MIMORI K, SADANAGA N, INOUE H, TANAKA Y et al. Prognostic impact of tissue inhibitor of matrix metalloproteinase-1 in esophageal carcinoma. Int J Cancer 2000; 88: 575-578. http://dx.doi.org/10.1002/10970215(20001115)88:4<575::AID-IJC9>3.0.CO;2-C

[52] LI M, XIAO T, ZHANG Y, FENG L, LIN DM et al. Prognostic significance of matrix metalloproteinase- 1 levels in peripheral plasma and tumour tissues of lung cancer patients. Lung Cancer 2010; 69: 341-347. http://dx.doi.org/10.1016/j.lungcan.2009.12.007 
doi:10.4149/neo_2015_006

\title{
Supplementary Information
}

\section{Fn14 receptor promotes invasive potential and metastatic capacity of non-small lung adenocarcinoma cells through the up-regulation of integrin $a 6$}

\author{
J. JANDOVA ${ }^{1,2^{*}}$, C. J. MASON ${ }^{1}$, S. C. PAWAR ${ }^{1,3}$, G. S. WATTS ${ }^{1,3}$
}

${ }^{1}$ University of Arizona Cancer Center and Departments of ${ }^{2}$ Medicine - Dermatology Section and ${ }^{3}$ Pharmacology, University of Arizona, Tucson, AZ 85724, USA

*Correspondence: jjandova@email.arizona.edu

\section{Supplementary Figure}
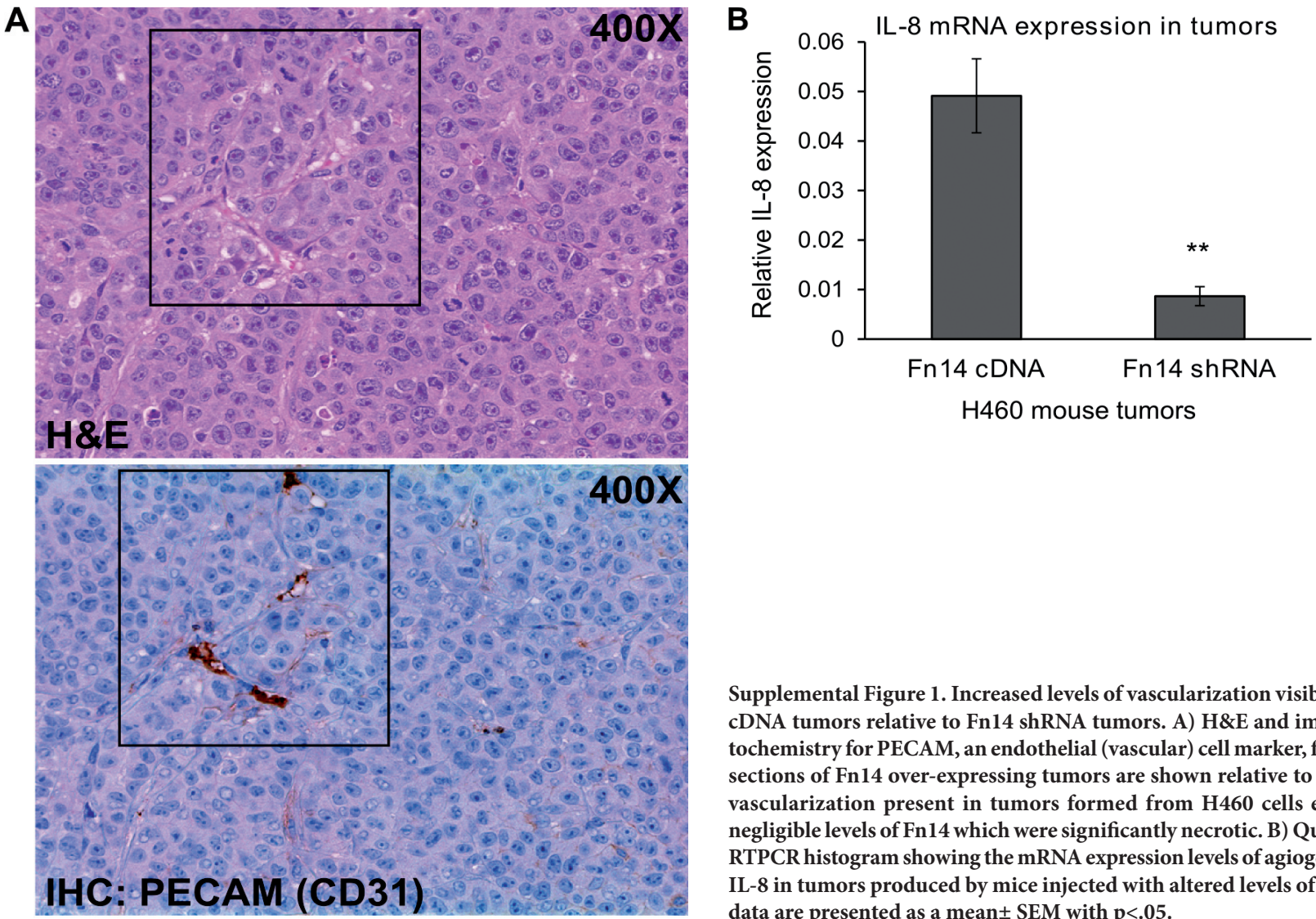

\begin{abstract}
Supplemental Figure 1. Increased levels of vascularization visible in Fn14 cDNA tumors relative to Fn14 shRNA tumors. A) H\&E and immunohistochemistry for PECAM, an endothelial (vascular) cell marker, from serial sections of Fn14 over-expressing tumors are shown relative to almost no vascularization present in tumors formed from $\mathrm{H} 460$ cells expressing negligible levels of Fn14 which were significantly necrotic. B) Quantitative RTPCR histogram showing the mRNA expression levels of agiogenic factor IL-8 in tumors produced by mice injected with altered levels of Fn14. The data are presented as a mean \pm SEM with $\mathrm{p}<.05$.
\end{abstract}

